\title{
The Impact of Topic Selection on Writing Fluency:Making a Case for Freedom
}

Joshua Cohen

\begin{abstract}
This study sought to test the hypothesis that topic-selection control influences fluency in writing. A total of 29 second-year university students (9 men, 20 women) in two separate classrooms engaged in a free writing activity using different topics (both teacher-selected and self-selected) in order to determine which approach was more likely to increase writing fluency. Participants' written output was then textually analyzed for fluency using a type/token formula. A total of 116 samples written by participants over four weeks were examined to measure their writing fluency by counting the total number of unique words produced in a free writing task. Participants' writing samples were then analyzed by conducting a correlated-samples $t$-test. The results showed the effect of topic-selection had a statistically significant influence on increasing students' writing fluency. The results also support the claim that fluency development deserves a prominent role in second and foreign language classrooms and curriculums.
\end{abstract}

Key words: Fluency development; EFL writing; Free writing; Topic selection

\section{Introduction}

Writing fluency is a skill that, unfortunately, many foreign language learners lack. This inability can leave them feeling frustrated and even fearful of the act of writing (Cheng, 2004). However, fluency development activities have been shown to result in both language learning and skill gains (Chenoweth and Hayes, 2001). By measuring participants' 'burst length' in a writing task, the researchers showed that fluent (i.e., automatic) word production increased based on a writer's experience and familiarity with the language. The researchers also demonstrated that as writers' fluency increased, their capacity to produce longer, richer strings of text increased too. Other studies by Elley and Mangubhai (1981), Fellner and Apple (2006), and Perl (1979) also reported improvement in learners' ability to use language when the main goal was fluency development.

\section{Fluency}

Fluency refers to having ready access to what you already know. In their seminal work on automaticity, LaBerge and Samuels (1974) described fluency as an automatic process, which requires no conscious effort. Schmidt (1992) also referred to automaticity, arguing that fluency should be characterized by the ability to retrieve language forms 
immediately and without conscious searching. Brumfit (1984) asserted that fluency is associated with using language in a natural way and that continuity and speed are involved.

Nation (2007) has suggested that in a well-balanced second language (L2) course there are roughly equal opportunities for learning through four equal strands: meaning-focused input, meaning-focused output, focus on form, and fluency development. Nation's fourth strand, fluency development, calls for students to make the best use of what they already know by working with known content across the four skills of listening, reading, writing and speaking. Writing fluency development occurs when all of the materials learners use are largely familiar to them and come from a corpus of words and grammatical forms already internalized by them.

\section{Freewriting}

One classic writing fluency development procedure is freewriting. Elbow (1973) defined freewriting as an activity where one quickly writes without stopping, but does not rush, look back, cross anything out, or stop and wonder which word to use. During freewriting, participants are often instructed not to erase, not to use dictionaries or thesauruses, and to try writing whatever comes to mind regardless of how far-fetched it may seem. The goal of freewriting is to get as many thoughts down onto paper as quickly as possible.

There are a number of pedagogical benefits to setting aside time for freewriting. As a fluency building technique, freewriting can assist students in producing writing quantity and help them develop the ability to perform under pressure of time. It may also help them to generate and develop topics, improvise on themes, recognize ideas of which they may not have been previously aware, and helps them become more familiar and comfortable with the writing process in general (Jacobs, 1986). Busy teachers often employ freewriting because it is easy to set up and requires little maintenance to keep going.

Freewriting is also done in L2 classrooms, most commonly in the form of journal writing (Allison, 1998; Peyton \& Stanton, 1993; Spack \& Sadow, 1983). Another popular freewriting activity involves students writing as much as possible on a topic in a specified period of time. An intriguing component of this type of activity is the selection of the topic - either by the teacher or by the student. Bonzo (2008) investigated the effects of topic selection on writing fluency with a group of university students studying German in the United States. His study demonstrated a strong correlation between both grammatical and lexical complexity and participants' general writing fluency, regardless of whether the topic was self-selected or teacher selected. This study's main goal was to better understand the influence of topic selection on writing fluency with students studying English as a foreign language in Japan.

\section{Purpose of the study}

Although most modern language curriculums place a high premium on speaking and reading fluency

$32 \quad$ Journal of NELTA, Vol 18 No. 1-2, December 2013 
development, very little time is devoted to developing writing fluency. According to Brown (1990), for learners to become more proficient in writing they need the opportunity to write and the motivation to do so. Presently when writing from learners is called for, teachers, tests, and textbooks typically determine the topic and setting in which language learners must comply. However, Hinkel (2009) found that participant output was significantly affected by the writing topic alone. If this is true, then teachers and textbook writers need to be more cognizant of the content students find engaging and which topics will produce the greatest results.

\section{Research question}

To answer the question of what types of topics tend to motivate students the most, this study focused on the following research question:

Does topic-selection control (either selfselected or teacher-selected) during a timed freewriting activity influence participants' writing fluency as calculated by a general fluency score?

\section{Methodology}

\section{Participants}

The participants were 29 second-year students enrolled in two business communication courses at a large, private university in western Japan. The students were not randomly assigned, but formed samples of convenience. One class consisted of 13 students and the other class had 16 students. The students' years of formal English instruction (i.e. English learned in an academic setting) ranged between seven and nine, but were considered low by tested proficiency with English. The mean TOEFL PBT score for the students was $469(S D=20.46)$. Twenty-eight were native speakers of Japanese and one spoke Chinese as a first language. Ten were men and nineteen were women (although first language and gender were neither controlled for nor considered as variables in the study). Age too, was neither controlled for nor considered as a variable; however all of the participants were at least 19 years old. All the participants were majoring in Business Administration and all participants who took part in the study signed a consent form.

The ninety-minute long classes met twice a week for 15 weeks; however, the study described here lasted 4 weeks. The primary goal of the classes was to help students feel more comfortable thinking, speaking, and listening in English using business-related topics as the content base, but the course also aimed to help develop writing competence.

For the study, the two groups were counterbalanced with regard to topic selection to reduce any effects from the order of introduction. The control of topics was altered so that participants who selected freely in their first session were given a topic for their second session, while those who received a topic in their first session selected freely for their second session. Subsequent sessions and topics were alternated as shown in Table 1 below. 
Table 1: Design of the counter-balanced study

\begin{tabular}{|lll|}
\hline Session & Group Green & Group Blue \\
One & Self-selected & Life after graduation \\
Two & Life after graduation & Self-selected \\
Three & Self-selected & Favorite class \\
Four & Favorite class & Self-selected \\
\hline
\end{tabular}

\section{Procedure}

Shortly after the start of the spring semester, the two groups of students received detailed explanations about what freewriting is, how they should do it, and how it can be beneficial in developing writing fluency. A brief outline of the research scheduled to take place was presented, and the students were assured that none of their efforts in the studywould be graded nor count in any way toward their final grade. On the same day, the students were given an opportunity to practice using a 'mock' freewriting exercise, which served as chance for them to familiarize themselves with the process.

The procedure for the activity was the same on each day (except for the first day). In an effort to prevent course content and classroom influence on students' production, the freewriting task always took place at the start of each class. The participants received handouts for each freewriting session informing them of the day's topic (see Appendix A) and then began the activity at once. The topics used in the study were the kind beginning language students are familiar with: 1) What is your favorite class? 2) Describe life after graduation. Students' self-selected topics covered a wide variety of subjects, including movies, part-time jobs, weekend plans, and birthdays.

There were no prewriting activities and a 10-minute time limit was strictly enforced. Using Elbow's (1973) tenets to freewriting as a guide, the researcher instructed participants to write without stopping and not to worry about any standards for their writing. To help keep them focused on the activity they were told not to use pencils, erasers, or dictionaries. No feedback was given on any of the freewriting completed by participants. If a participant missed a session, they were prompted to make up the missing data sample as quickly as possible. All makeup sessions took place in an empty classroom with the guidance of the researcher and under identical conditions.

\section{Data and analysis}

Upon completion of the final session, participants' output was prepared for analysis by the researcher. All of the essays were transcribed using standard word processing software. Any misspelled words were corrected provided, that the errors were identifiable to the researcher. The essays were also reviewed for inadmissible words. Common Japanese loan words, such as karaoke and sushi were included as were any Japanese proper nouns. Romanized spellings of uncommon Japanese words (e.g., okonomiyaki, tencho) and words written in the Japanese kana systems (hiragana, katakana) or Chinese (kanji) characters were omitted from the data. The full guidelines for determining what qualified as a word are listed in Appendix B.

$34 \quad$ Journal of NELTA, Vol 18 No. 1-2, December 2013 
Next, the lexical diversity of each sample was established by differentiating between the number of types and tokens contained within each sample. Contractions were counted as two tokens, however words with the possessive "s" were counted as one. Well-known acronyms (e.g., TOEFL) were also counted as one token (see Appendix $C$ for the guidelines on determining the uniqueness of a word). By way of example, the following sentence, 'On weekends my father always cooks because his cooking is much better than my mother's cooking.' contains 16 tokens and 14 types.

Although more research is needed measuring writing fluency, there is a great deal of literature focused on the assessment of writing proficiency (Connor-Linton, 1995; Polio, 1997; Raimes, 1985). These kinds of approaches may be effective when judging writing for skill or attention to form, but come up short when the subject of fluency is being measured.

In studies of spoken language, rate of production has become the benchmark most commonly used to measure fluency. However, Wolfe-Quintero, Inagaki, and Kim (1998) identified two additional ways of defining fluency in L2 language production: simple frequency counts (of a particular feature, structure, or unit) and more complex calculations, involving indices based on formulas, which then yield numerical scores. To quantify and assess participants' lexical diversity for this study, a fluency score was calculated using a type-token formula originally proposed by Carroll (1967):

$$
F=\frac{U}{\sqrt{2 T}}
$$

As illustrated above, fluency was established as a function of lexical diversity with the total number of word types (U) per square root of two times the total number of word tokens (T). Whereas typical type-token ratios simply divide the total number of word types by the total number of tokens (U/ $\mathrm{T})$, Carroll's formula accounts for variations in the total number of words produced. For example, using the standard type-token ratio, a participant who wrote 200 words with 100 different word types would receive the same score $(0.5)$ as a participant who wrote 50 words with 25 different word types $(100 / 200=25 / 50=0.5)$. To offset this kind of weakness Carroll suggested a more sensitive approach where the same participants would receive fluency scores of 5.0 and 2.5 respectively, thereby giving higher scores to participants who were able to produce more in the same amount of time.

After each participant's freewriting samples were calculated they were given a fluency score and the means for each score analyzed within each group. The mean scores for the two conditions (self-selected and teacher-selected topics) and two groups are summarized in Table 2 below. There was considerable variance in output between the conditions of teacherassigned topics and self-selected topics. In both groups the mean for selfselected topics was higher than that of teacher-selected topics. 
Table 2: Topic control and fluency

\begin{tabular}{|lllll|}
\hline Group & $\boldsymbol{n}$ & Topic control & mean & SD \\
Blue & 13 & Teacher-selected & 3.93 & .30 \\
Blue & 13 & Self-selected & 4.21 & .23 \\
Green & 16 & Teacher-selected & 4.18 & .50 \\
Green & 16 & Self-selected & 4.58 & .40 \\
Combined & 29 & Teacher-selected & 4.10 & .43 \\
Combined & 29 & Self-selected & 4.42 & .38 \\
\hline
\end{tabular}

\section{Results}

To determine the influence of topic control on production, a correlated samples $t$-test was conducted. There was a significant difference in the scores for teacher-selected $(M=4.10, S D=.43)$ and self-selected topic $(M=4.42, S D=.38)$ conditions; $t(28)=-6.18, p<.0001$. These results suggest that topic-selection control has a positive effect on writing fluency. Specifically, the results suggest that when students are granted the freedom to select their own topics, they write more and use a larger variety of words to express themselves. In other words, their writing fluency increases.

\section{Discussion}

This study investigated the influence topic-selection control has on fluency in timed, unplanned, L2 freewriting. The dependent variable in the study, participants' fluency scores, was significantly influenced by the control of the topic. It did not matter whether participants first self-selected a topic or had one assigned to them; their fluency scores were significantly higher when writing was elicited from a self-selected topic. In other words, participants wrote more and with greater lexical variety when they were free to choose their own topics rather than being assigned one.

There are a number of possible explanations why participants' writing fluency increased when self-selecting a topic. The absence of topical boundaries may have given them the confidence to explore areas they might have otherwise avoided when writing with an assigned topic. Conversely, teacher-selected topics may have inhibited participants' from using their full range of vocabulary and syntax. A recent study by Hinkel (2009) looked at writings done by L2 speakers of Chinese, Japanese, and Korean and found evidence that topic selection had a direct influence on the use of certain grammatical features and word choices.

Another possible explanation is that participants may have felt topics of their own choice were easier to write about than topics assigned to them. Holmes and Moulton (1997) found that specific attributes of L2 journal writing (e.g. topic choice, frequency, and spontaneity) led students to believe that self-selecting a writing topic was related to their increased ability to write more fluently. Their research lends credibility to the notion that freedom of choice and affect may be closely associated.

That participants in each group wrote more when they chose the topic may not account for all the factors involved in writing production. This study did not test nor take into account brainstorming, circumlocution, pre-writing, grammatical complexity, or use of metacognitive strategies, all of which could be factors in producing differing levels of text. Participants in this study received a 
fluency score, which was established as a measure of two times the total number of produced words divided by the square root of the total number of words. Simply writing more is not in and of itself an accurate measure of fluency, but does suggest that learners in beginning level classrooms should be given some control and freedom over the topics they write about.

\section{Limitations}

Although this study reached its goal, a number of limitations must be considered. First, the research was conducted with low-level students and lasted only four weeks. Such a short amount of time may not be sufficient to obtain a representative sample of the effect topic-selection has on fluency. Future studies should take place over longer periods of time and be replicated with students from a variety of firstlanguage backgrounds and secondlanguage proficiency. Second, there was a relatively small sample size. The findings reported here may not be generalizable to the broader community of language learners at large. Third, this study did not consider the lexical complexity of participants' output. Future studies might investigate how grammatical accuracy or word difficulty changes between free-choice and teacher-selected topics. Fourth, learner individual differences such as affect, motivation, and the overall ability to write in L2 may have influenced the amount participants generated with regard to fluency. There were no measures taken to account for these kinds of differences.
This study was also limited by the absence of qualitative questions such as whether participants enjoyed freewriting or the topics presented to them. It is possible that different topics or a different format may have different results on participants' output.

\section{Conclusion}

The age-old adage, practice makes perfect is likely a familiar one. Successful actors, athletes, and musicians are all aware of it; it is what drives them to practice their craft so relentlessly. Fortunately, the key principle shown to be effective in training for sports and music can also be applied to the study of foreign language. For students to reach their goal of becoming proficient and skilled language users they need frequent opportunities to practice. Brumfit (1985) has suggested that as much as a full-third of an entire course be devoted to fluency activities with gradual increases occurring as the class progresses. Although curriculum demands may restrict the amount of time available for such training, it makes good pedagogical sense to devote as much time as possible to fluency training activities.

Setting aside time for learners to practice writing is a solid first step toward their mastering the process. Exposing them to meaningful and authentic content is a logical next step. The last step is for teachers to fully engage their students by giving them the freedom and responsibility to choose the content of their study. In shifting the responsibility to the learners, 
teachers and learners alike can feel confident they are taking steps toward fluency development and the mastery of a foreign language. As evidenced by the results of this study, simply shifting the control of topic choice can have profound results on learner output in terms of quantity. Future research may address the effect topic control has on accuracy and complexity.

\section{About the author}

Joshua Cohen teaches English in the Intensive International Program in the Faculty of Business Administration at Kinki University. His professional interests include ELT, reading fluency development, and L2 writing.

\section{References}

Alison, D. (1998). Investigating learners' course diaries as explorations of language. Language Teaching Research, $2(1), 24-47$.

Bonzo, J.D. (2008). To assign a topic or not: Observing fluency and complexity in intermediate foreign language writing. Foreign Language Annals, 41(4), 722-735.

Brown, H.D. (1990). M and Ms for language classrooms? Another look at motivation. In J. E. Alatis (Ed.), Georgetown University round table on language and

linguistics. 383-393. Washington DC: Georgetown University Press. Accessed April 25 $5^{\text {th }}, 2013$ from: http:/ /www.er.uqam.ca/nobel/r26710/ LRCS/papers/104.pdf

Brumfit, C. J. (1984).Communicative methodology in language teaching: The roles of fluency and accuracy. Cambridge: Cambridge University Press.

Brumfit, C. J. (1985). Accuracy and fluency: a fundamental distinction for communicative teaching methodology, in C.J. Brumfit, Language and literature teaching: From practice to principle. Oxford: Pergamon.

Carroll, J. B. (1967). On sampling from a lognormal model of word-frequency distribution. In H. Kucera \& W. N. Francis (Eds.), Computational analysis of present-day American English. (pp. 406-424). Providence, RI: Brown University.

Cheng, Y.S. (2004). A measure of secondlanguage anxiety: Scale development and preliminary validation. Journal of Second Language Writing, 13, 313-335.

Chenoweth, N. A. \& Hayes, J.R. (2001). Fluency in Writing: Generating Text in L1 and L2. Written Communication. 18(1), 80-98.

Connor-Linton, Jeff. (1995). Crosscultural comparison of writing standards: American ESL and Japanese EFL. World Englishes, 14, 99-115.

Elbow, P. (1973). Writing without Teachers. New York, NY: Oxford University Press.

Elley, W.B. \& Mangubhai, F. (1981). The Impact of a book flood in Fiji primary schools. Wellington: New Zealand Council for Education Research.

Fellner, T. \& Apple, M. (2006). Developing writing fluency and complexity with blogs. The JALT CALL Journal, 2, (1) 1526. Accessed January 15, 2013 from: http://journal.jaltcall.org/articles/ 2_1_Fellner.pdf

Hinkel, E. (2009).The effects of essay topics on modal verb uses in L1 and L2 academic writing. Journal of Pragmatics, 41, 667-683. 
Holmes, V. L. \& Moulton, M.R. (1997). Dialog journals as an ESL learning strategy. Journal of Adolescent and Adult Literacy, 40(8), 616-621.

Jacobs, G. (1986). Quickwriting: a technique for invention in writing. ELT Journal, 40(4), 282-290.

Laberge, D., \& Samuels, S. (1974). Toward a theory of automatic information processing in reading. Cognitive Psychology, 6, 293-323.

Nation, I.S.P. (2007). The four strands. Innovation in Language Learning and Teaching, 1(1), 1-12.

Perl, S. (1979).The Composing Processes of Unskilled College Writers. Research in the Teaching of English, 13(4), 317-336.

Peyton, J.K. \& Stanton, J. (1993). Resource guide: A dialog journal bibliography. Washington, D.C.: NCLE Accessed April $28^{\text {th }}, 2013$ from: http:/ / files.eric.ed.gov/ fulltext/ED451731.pdf

Polio, C.G. (1997). Measures of linguistic accuracy in second language writing research. Language Learning, 47(1), 101143.

Raimes, A. (1985). What do unskilled ESL writers do as they write: A classroom study of composing. TESOL Quarterly, 19(2), 229-258.

Schmidt, R. (1992). Psychological mechanisms underlying language fluency. Studies in Second Language Acquisition, 14, 357-385.

Spack, R. \& Sadow, C. (1983). Student-teacher working journals in ESL freshman Composition. TESOL Quarterly, 17(4), 575-593.

Wolfe-Quintero, K., Inagaki, S., \& Kim, H. (1998). Second language development in writing: Measures of fluency, accuracy $\mathcal{E}$ complexity. Honolulu, HI: University of Hawai'i Press.
Appendix A

\begin{tabular}{|c|}
\hline $\mathrm{T}$ \\
\hline $\mathrm{U}$ \\
\hline Do not write here \\
\hline
\end{tabular}

ID Number:

Class:

\section{Freewriting}

In "Freewriting," you have a limited amount of time to write as much as you can. This activity is designed to increase your fluency in writing. Please be sure you write in pen only. Do not use an eraser, instead cross out any words you don't like. Please refrain from using your dictionary.

\section{TOPIC: Life after graduation}

\section{Appendix B}

Rules for what counted as a word (Tokens)

Misspelled words that could be identified by closeness to the correct spelling or by context were counted. (e.g. whare for where)

- Contractions were counted as two words (e.g. you' re was two words)

- Japanese words commonly used in English (e.g. kimono) counted towards the total.

- Words were counted even if they did not fit into a sentence, e.g. a bulleted list.

- Names were counted based on number of words in the name. (e.g. Brad Pitt was two words) 
Rules for what did not count as a word (Tokens)

- Romanized spellings of katakana English loan words were not counted. (e.g. resutoran for restaurant)

- Kana spellings of katakana English loan words were not counted. (e.g. ìn010È0é0ó0)

- Romanized spellings of true Japanese words were not counted (e.g. inu)

- Kanji did not count as words. (e.g. $\mathrm{qg}^{\prime} \mathrm{Y}^{*}-$ did not count )

- Scratched out words did not count as words.

\section{Appendix C}

Rules for deciding the uniqueness of a word (Types)

- Different forms of the same word were counted as different words (e.g. run and ran were two words)

- Homonyms were counted separately (e.g. left = leave and left = opposite of right are two unique words).

- A misspelled word was not a unique word (e.g. whare and where counted as one unique word)

- Different usages of the same word were counted as separate words (e.g. to work and work (place) 